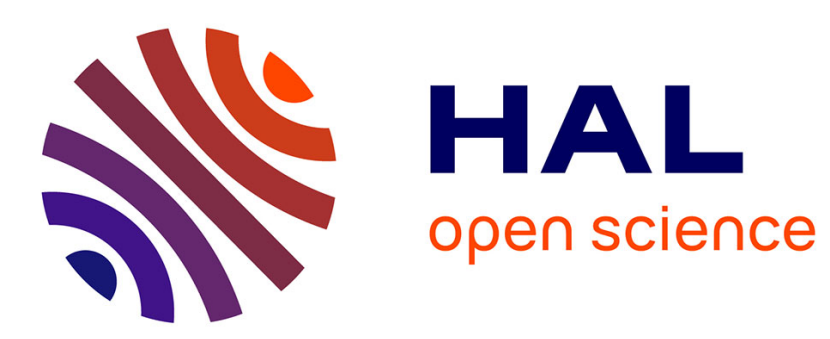

\title{
New kinetic model for the rapid step of calcium oxide carbonation by carbon dioxide
}

\author{
Lydie Rouchon, Loïc Favergeon, Michèle Pijolat
}

\section{To cite this version:}

Lydie Rouchon, Loïc Favergeon, Michèle Pijolat. New kinetic model for the rapid step of calcium oxide carbonation by carbon dioxide. Journal of Thermal Analysis and Calorimetry, 2014, 116 (3), pp.1181-1188. 10.1007/s10973-013-3544-y . hal-01009674

\section{HAL Id: hal-01009674 https://hal.science/hal-01009674}

Submitted on 18 Jun 2014

HAL is a multi-disciplinary open access archive for the deposit and dissemination of scientific research documents, whether they are published or not. The documents may come from teaching and research institutions in France or abroad, or from public or private research centers.
L'archive ouverte pluridisciplinaire HAL, est destinée au dépôt et à la diffusion de documents scientifiques de niveau recherche, publiés ou non, émanant des établissements d'enseignement et de recherche français ou étrangers, des laboratoires publics ou privés. 


\title{
New kinetic model for the rapid step of calcium oxide carbonation by carbon dioxide
}

Authors: Lydie Rouchon, Loïc Favergeon, Michèle Pijolat

\section{Affiliations:}

École Nationale Supérieure des Mines, SPIN-EMSE, PRESSIC Department, CNRS:UMR5307, LGF F-42023 Saint-Étienne, France

\section{Corresponding author:}

Loïc Favergeon, École Nationale Supérieure des Mines de Saint-Étienne, 158 Cours Fauriel, 42023 Saint-Étienne, Cedex 2, France, e-mail address: favergeon@emse.fr ; phone number: +33477420293; fax number : +33477499694.

\section{Keywords:}

Carbonation, Calcium oxide, Kinetic modeling, TG

\begin{abstract}
Carbonation of solid calcium oxide by gaseous carbon dioxide was monitored by thermogravimetry (TG). A kinetic model of $\mathrm{CaO}$ carbonation is proposed in order to interpret the first rapid step of the reaction. By taking into account the existence of large induction period as well as the sigmoidal shape of the kinetic curves in this kinetic-controlled region, a surface nucleation and isotropic growth kinetic model based on a single nucleus per particle is proposed and the expressions of the fractional conversion and the reaction rate versus time are detailed. The induction period is found to have a linear variation with respect to temperature and to follow a power law with respect to $\mathrm{CO}_{2}$ partial pressure. The areic reactivity of growth decreases with temperature increase, and increases with $\mathrm{CO}_{2}$ partial pressure increase. A
\end{abstract}


mechanism of $\mathrm{CaCO}_{3}$ growth is proposed to account for these results and to determine a dependence of the areic reactivity of growth on the temperature and the $\mathrm{CO}_{2}$ partial pressure.

\section{Introduction}

Carbonation of $\mathrm{CaO}$ reaction is involved in the carbonation/decarbonation cycles which are known as a possible way of $\mathrm{CO}_{2}$ capture. It was shown that the most important limitations of carbonation process are related to the reversibility of the reaction. $\mathrm{CaO}$ rapidly loses its activity towards $\mathrm{CO}_{2}$, so the maximum extent of carbonation decreases as the number of carbonation cycles increases.

Several experimental studies were reported in the past on the reaction of $\mathrm{CaO}$ carbonation. Bathia et al. [1] have reported that the carbonation curve has a sigmoidal shape with a rapid first step and a slow second step. Bathia et al. [1], Silaban et al. [2] and Bouquet et al. [3] explained this shape by a decrease in porosity and Abanades et al. [4] by the formation of a layer of $\mathrm{CaCO}_{3}$ covering $\mathrm{CaO}$ aggregates. The effects of the experimental conditions on $\mathrm{CaO}$ carbonation were also studied. Thus, Nikulshina et al. [5] showed an acceleration of the rapid step and a higher final conversion when temperature increased. Grasa et al. [6] showed that increase of $\mathrm{CO}_{2}$ partial pressure resulted in acceleration of the rapid step. Some studies have also been conducted on the effect of $\mathrm{H}_{2} \mathrm{O}$ partial pressure and Nikulshina et al. [5] demonstrated that increase in $\mathrm{H}_{2} \mathrm{O}$ partial pressure had an accelerating effect. Finally, it has been shown that the decarbonation conditions of $\mathrm{CaCO}_{3}$ were important and $\mathrm{CaO}$ sintering inhibited carbonation [7].

If numerous studies were performed to determine the influence of experimental conditions on carbonation reaction, much fewer studies dealt with kinetic modeling of $\mathrm{CaO}$ carbonation. Two different scales of modelling were considered: 
- at the grain scale, authors based their interpretations on the shrinking core model. Thus, Sun et al. [8] applied this model to only a short linear part. Bouquet et al. [3] also used this model and explained the first step of carbonation;

- at the aggregate scale, the gradient of $\mathrm{CO}_{2}$ partial pressure inside aggregate pores and the closing of pores were considered. So, Bathia et al. [1] applied the random pore model and Sun et al. [9] performed a coupling between random pore model and grain model with a discrete pore size distribution. Nevertheless, the random pore model did not allow to represent the entire curves, and in Sun's study, the results were not totally satisfactory at low temperature and low $\mathrm{CO}_{2}$ partial pressure.

In a previous paper [10] we have described a complex behavior of $\mathrm{CaO}$ carbonation kinetics. The " $\phi S_{\mathrm{m}}$ " test [12] clearly showed that the reaction path passes through three distinct kinetic domains over the entire range of fractional conversion. Thus the $\mathrm{CaO}$ carbonation reaction kinetics can be decomposed into three successive domains, the first and the last ones being governed by a rate-determining step of growth, the intermediate one resulting from a mixed regime of reaction and gaseous diffusion through the pores. First, the reaction begins at the grain scale and the kinetics is governed by a rate-determining step in all parts of the aggregates; the corresponding range of fractional conversion varies from $0-0.15$ to $0-0.4$ when the temperature increases from 450 to $550^{\circ} \mathrm{C}$. In the intermediate domain the reaction follows a non-Arrhenius behavior, explained by approaching the $\mathrm{CaO}-\mathrm{CaCO}_{3}$ equilibrium conditions into the pores due to increasing pressure gradients as far as the reaction proceeds. In the last domain, another rate-determining step governs the kinetic behavior, which could be due to porosity closure at the periphery of the aggregates; at this time, diffusion through a dense $\mathrm{CaCO}_{3}$ shell around the aggregates should be involved, as proposed by Mess et al. [11].

The present work was undertaken to interpret kinetic data in the first domain cited above with a model involving both nucleation and growth processes to account for the initial accelerating 
part of the fractional conversion $\alpha$ dependence on time curves. Indeed in this domain, the gaseous transfer into the aggregates porosity is supposed to be rapid and assuming that a steady-state is established since the beginning of the reaction, the reaction rate can be written as follow:

$$
\frac{\mathrm{d} \alpha}{\mathrm{d} t}=\phi\left(T, P_{i}, \ldots\right) S_{\mathrm{m}}(t, \ldots)
$$

where $\phi\left(T, P_{\mathrm{i}}, \ldots\right)$ is the areic reactivity of growth (in mol $\mathrm{m}^{-2} \mathrm{~s}^{-1}$ ) which depends only on the thermodynamic variables, and the $S_{\mathrm{m}}(t)$ molar space function is time-dependant (expressed in $\mathrm{m}^{2} \mathrm{~mol}^{-1}$ ) and is related to the extent reaction area where the rate-determining step of growth takes place.

This paper presents the kinetic model developed to explain the experimental data, especially in the case of slow nucleation and rapid growth. The description of this model and the mathematical expressions of both the fractional conversion and the reaction rate versus time are detailed. Finally the comparison between kinetic model and experimental results are presented and variations of induction period and areic reactivity of growth with temperature and $\mathrm{CO}_{2}$ partial pressure are obtained.

\section{Experimental kinetic curves}

\subsection{Kinetic curves}

Using a symmetrical TG system (Setaram TAG 16), the kinetic data of $\mathrm{CaO}$ carbonation were recorded with a sample of about $10 \mathrm{mg}$. The $\mathrm{CaO}$ powder used in this study was obtained in situ from the thermal decomposition of $\mathrm{CaCO}_{3}$ powder supplied by Prolabo Corp. with a purity of $99.5 \mathrm{wt} \%$. The entire experimental procedure is described elsewhere [10]. This way, 
we performed carbonation reaction under isothermal and isobaric conditions for temperatures in the range of $450-650^{\circ} \mathrm{C}$ and $\mathrm{CO}_{2}$ partial pressures in the range of $2-30 \mathrm{kPa}$.

Figures 1 and 2 present the dependence of the fractional conversion on time of reaction obtained at various temperatures and $\mathrm{CO}_{2}$ partial pressures, respectively. All the kinetic curves exhibit a similar shape and can be divided into three stages: first an induction period, then a very fast carbonation stage up to a breakpoint and finally a sluggish stage up to the end. The duration of the induction period depends on the experimental conditions of temperature and $\mathrm{CO}_{2}$ partial pressure.

\section{Description of the kinetic model}

The kinetic curves reveal the existence of an induction period which is sometimes longer than the rapid step of carbonation (until the kinetic slowing down). It is well admitted that induction periods are linked to the nucleation process, typically to the time required for appearance of nuclei. The presence of large induction periods indicates that the nucleation process can be sluggish depending on experimental conditions. This observation can be correlated with an ab initio study of the calcite nucleation at the $\mathrm{CaO}$ surface [14] which has shown that nucleation can be a tricky process on some surfaces due to strong structural instabilities related with $\mathrm{CO}_{2}$ insertion. Indeed the (100) surface of the $\mathrm{CaO}$ crystal appears unfavorable for nucleation whereas the (111) surface emerges as much more stable for $\mathrm{CO}_{3}$ incorporation. Since the (100) surface is the most stable and the (111) surface is the least stable of $\mathrm{CaO}$ low index surfaces $[15,16]$, nucleation of $\mathrm{CaCO}_{3}$ at the $\mathrm{CaO}$ surface may thus be a very difficult process. Moreover, the sharp accelerating shape of the $\alpha$ versus time curves indicates that the nuclei which appear at the end of the induction period are really numerous. So on one hand, the nucleation process takes a long time to occur and on the other hand, the time necessary to transform most of the grains due to growth is of the same order as the 
induction period. These considerations led us to base the kinetic model on the assumption that only one nucleus appears at the surface of a dense grain.

After the induction period, kinetic curves $\alpha(t)$ exhibit a fast carbonation step with a sigmoid shape. This sigmoid shape is characterized by an acceleratory period followed by a deceleratory one. In isothermal and isobaric conditions, the areic reactivity of growth $\phi$ remains constant and Eq. (1) indicates that the reaction rate varies with time only due to the variation of the $S_{\mathrm{m}}$ function. Assuming that the rate-determining step is an interfacial step, the variation of $S_{\mathrm{m}}$ with time corresponds to the variation of the area of this interface. At the same time as the reaction rate increases then decreases, this area increases then decreases. Given that there is only one nucleus per grain, the only possibility path for such an interface area to increase then decrease is an isotropic and inward growth with a rate-determining step located at the internal $\mathrm{CaO} / \mathrm{CaCO}_{3}$ interface.

So, to describe the phenomena occurring into the second stage of the kinetic curves, we based our model on six hypothesis : i) only one nucleus appears at the surface of each grain ; ii) the nuclei appear at same time on all grains ; iii) the growth of the nuclei is isotropic (same rate in all the directions of the space); iv) grains are spherical with the same initial radius $r_{0}$; v) the direction of growth is inwards ; vi) the rate-determining step is located at the internal interface.

Figure 3 shows a schematic representation of one grain partially transformed with these previous assumptions.

\section{Mathematical expression of the kinetic rate}

Due to the previously mentioned hypothesis i) and ii), the calculation of the rate $\mathrm{d} \alpha / \mathrm{d} t$ corresponding to the entire sample may be obtained from the calculation done for a single 
grain since all the grains will be transformed in the same manner. We have shown in the 'introduction' section that the reaction rate can be expressed by Eq. (1) where $\phi$ is the areic reactivity of growth (in $\mathrm{mol} \mathrm{m}^{-2} \mathrm{~s}^{-1}$ ) and $S_{\mathrm{m}}$ is the molar space function (expressed in $\mathrm{m}^{2} \mathrm{~mol}^{-}$ $\left.{ }^{1}\right)$. The six assumptions chosen in the previous section allow to determine the expression of the space function $S_{\mathrm{m}}$. Indeed $S_{\mathrm{m}}$ is linked with the area of the zone where the ratedetermining step occurs. In our case this zone is the internal interface between $\mathrm{CaO}$ and $\mathrm{CaCO}_{3}$

In order to calculate the expression of the reaction rate dependence on time, it is interesting to express the rate in two different ways: using the expression of the rate based on Eq. (1) and using the rate at which the $\mathrm{CaO}$ volume decreases.

The calculation of the rate of $\mathrm{CaO}$ volume change is based on the evaluation of the area of the $\mathrm{CaO} / \mathrm{CaCO}_{3}$ interface, noted $S_{\mathrm{i}}$. According to the scheme of Fig. $4, S_{\mathrm{i}}$ corresponds to the surface of a spherical cap which has for center the $G$ point where the nucleus appeared. This spherical cap has a radius $r$ at time $t$. Thus $S_{\mathrm{i}}$ can be calculated by considering the solid angle $\Omega$ of the cone with apex angle $2 \theta . S_{\mathrm{i}}$ is expressed by:

$S_{\mathrm{i}}=\Omega r^{2}$

with $\Omega=2 \pi(1-\cos \delta)$

where $\delta$ is the angle between $\mathrm{CG}$ and MG. If $r_{0}$ is the initial radius of the $\mathrm{CaO}$ dense grain, since $\cos \delta$ is equal to the ratio $\frac{r}{2 r_{0}}$, the expression of $S_{\mathrm{i}}$ becomes:

$$
S_{i}=2 \pi r^{2}\left(1-\frac{r}{2 r_{0}}\right)
$$


Given that the rate-determining step of carbonation is assumed to occur at the internal interface and that $S_{\mathrm{m}}$ is by definition equal to the ratio of $S_{\mathrm{i}}$ to the initial amount of $\mathrm{CaO}$ in the grain [17], the expression of the reaction rate $\mathrm{d} \alpha / \mathrm{d} t$ is obtained by substituting the expression of $S_{\mathrm{m}}$ into Eq. (1), which gives:

$$
\frac{\mathrm{d} \alpha}{\mathrm{d} t}=\frac{2 \pi \phi}{n_{0}} r^{2}\left(1-\frac{r}{2 r_{0}}\right)
$$

where $\mathrm{n}_{0}$ is the initial amount of $\mathrm{CaO}$ and $r_{0}$ the initial radius of the dense grain of $\mathrm{CaO}$.

The rate at which the $\mathrm{CaO}$ volume decreases is given by:

$$
-\frac{\mathrm{d} V_{C a O}}{\mathrm{~d} t}=S_{i} \frac{\mathrm{d} r}{\mathrm{~d} t}
$$

Given that:

$$
\frac{d \alpha}{d t}=\frac{1}{n_{0}} \frac{d \xi}{d t}=\frac{1}{n_{0} V_{m, \mathrm{CaO}}}\left(\frac{-d V_{\mathrm{CaO}}}{d t}\right)
$$

where $\xi$ is the extent of reaction and $\mathrm{V}_{\mathrm{m}, \mathrm{CaO}}$ is the molar volume of $\mathrm{CaO}$, and combining Eqs. (4), (5) and (6), the relationship between $\mathrm{d} r$ and $\mathrm{d} t$ can be written:

$\mathrm{d} r=V_{m, C a O} \phi \mathrm{d} t$

By integrating between 0 and $r$ for $t$ between $\tau$ and $t$ ( $\tau$ is the induction period and corresponds to the date of birth of the nucleus), the expression of $r$ can be obtained:

$$
r=V_{m, C a O} \phi(t-\tau)
$$

The expression of $\mathrm{d} \alpha / \mathrm{d} t$ is given from Eqs. (4) and (8): 


$$
\frac{\mathrm{d} \alpha}{\mathrm{d} t}=\frac{2 \pi V_{m, \mathrm{CaO}}^{2} \phi^{3}}{n_{0}}(t-\tau)^{2}\left(1-\frac{V_{m, \mathrm{CaO}} \phi}{2 r_{0}}(t-\tau)\right)
$$

As $n_{0}=\frac{V_{0}}{V_{m, \mathrm{CaO}}}=\frac{4}{3} \pi \frac{r_{0}^{3}}{V_{m, \mathrm{CaO}}}$, the rate of reaction is expressed by:

$$
\frac{\mathrm{d} \alpha}{\mathrm{d} t}=\frac{3 V_{m, C a O}^{3} \phi^{3}}{2 r_{0}^{3}}(t-\tau)^{2}\left(1-\frac{V_{m, C a O} \phi}{2 r_{0}}(t-\tau)\right)
$$

By integration, the expression of the fractional conversion $\alpha$ is then:

$$
\alpha=\frac{V_{m, \mathrm{CaO}}^{3} \phi^{3}}{2 r_{0}^{3}}(t-\tau)^{3}\left(1-\frac{3 V_{m, \mathrm{CaO}} \phi}{8 r_{0}}(t-\tau)\right)
$$

The surface nucleation and isotropic growth model with a single nucleus per grain leads to sigmoïdal $\alpha(t)$ curves. In fact, it is easy to see from Fig. 3 that the area of the $\mathrm{CaO} / \mathrm{CaCO}_{3}$ interface passes through a maximum as far as the growth of $\mathrm{CaCO}_{3}$ progresses inside the grain.

The expressions of the fractional conversion (Eq. (11)) and the reaction rate (Eq. (10)) dependence on time involve four values: the molar volume of $\mathrm{CaO}$ which is equal to $1.6710^{-}$ ${ }^{5} \mathrm{~m}^{3} \mathrm{~mol}^{-1}$, the initial radius of $\mathrm{CaO}$ grains which was previously determined by SEM observations and which was about $1 \mu \mathrm{m}$ for all of the individual grains [10], and finally the areic reactivity of growth, $\phi$, and the induction period, $\tau$, used as the adjustable kinetic parameters when comparing the model to the experimental curves. The numerical fitting has to be done up to a value which corresponds to the frontier between domains I and II as determined in our previous article from the " $\phi S_{\mathrm{m}}$ " test [10]. These limiting values are reported in Table 1, beyond them the model is not applicable due to a change in the kinetic 
regime to reaction-gas diffusion mixed regime. The values of the areic reactivity of growth $\phi$ and of the induction period $\tau$ can thus be determined for each experimental settled condition.

It is thus possible to obtain the changes of both the areic reactivity of growth and the induction period dependence on $\mathrm{CO}_{2}$ partial pressure and temperature of carbonation.

\section{Results and discussion}

For each experimental condition, the values of both the areic reactivity of growth, $\phi$, and the induction period, $\tau$, are adjusted by the least squares method in order to obtain the best agreement between both the calculated curves and the experimental ones.

\subsection{Results of optimization}

Optimizations using both parameters, $\phi$ and $\tau$, have been performed for experimental data obtained for various temperatures in the range $450-650^{\circ} \mathrm{C}$ and various $\mathrm{CO}_{2}$ partial pressures in the range 2-30 $\mathrm{kPa}$. As noted previously the fitting has been done from $\alpha$ equal to zero up to the fractional conversion given in Table 1 for each experimental condition.

Experimental and calculated kinetic curves $\alpha(t)$ and rate curves $\mathrm{d} \alpha / \mathrm{d} t(\alpha)$ are shown in Figure 5 for experiments carried out at $723 \mathrm{~K}$ under $30 \mathrm{kPa}$ of $\mathrm{CO}_{2}$ and at $873 \mathrm{~K}$ under $5 \mathrm{kPa}$ of $\mathrm{CO}_{2}$.

Figure 5 shows that, for each temperature or $\mathrm{CO}_{2}$ partial pressure, experimental points are correctly described by the isotropic growth model with 1 nucleus per grain in the first domain (this first domain is represented in grey on the Fig. 5). Table 1 lists, for each condition of temperature and $\mathrm{CO}_{2}$ partial pressure, the values of the areic reactivity of growth and of the induction period

As it can be seen in Table $1, \mathrm{CO}_{2}$ partial pressure has an effect on the duration of the induction period: the higher the $\mathrm{CO}_{2}$ pressure, the shorter the induction period. The variation 
amplitude is very important for pressures from 2 to $5 \mathrm{kPa}$ of $\mathrm{CO}_{2}$, but much less important between 5 and $30 \mathrm{kPa}$.

Only three $\mathrm{CO}_{2}$ partial pressures were studied by thermogravimetry at temperature $\mathrm{T}_{0}=923 \mathrm{~K}$. However, a power law seems to fit the experimental points, as shown in Fig. 6. The change in the induction period with the $\mathrm{CO}_{2}$ partial pressure therefore seems to be mathematically described by the following law:

$\tau_{P}(P)=4.0610^{5} P^{-0.724}$

with $P$ in $\mathrm{Pa}$.

The effect of the temperature of carbonation on the induction period has also been studied at a $\mathrm{CO}_{2}$ partial pressure $\mathrm{P}_{0}=5 \mathrm{kPa}$. Figure 7 shows that induction period linearly increases when temperature increases. Indeed, the change in the induction period in function as a temperature can be described by the following linear law:

$\tau_{T}(T)=3.3069 T-2387.6$

with $T$ in Kelvin.

The values of the induction periods obtained here by kinetic modeling $\tau_{\text {simulation }}$ can be compared with experimental values $\tau_{\exp }$ previously determined [10] using the time elapsed from the $\mathrm{CO}_{2}$ partial pressure equilibration ( 3 min after $\mathrm{CO}_{2}$ introduction) until the mass gain began to exceed the thermobalance noise $(\Delta m<1 \mu \mathrm{g})$. These values of $\tau_{\exp }$ are given in Table 1. One can note that $\tau_{\exp }$ and $\tau_{\text {simulation }}$ are quite similar, which makes the numerical fitting procedure reliable.

From Eqs. (12) and (13), it was derive Eq. (14) describing the variation of $\tau$ versus both temperature and $\mathrm{CO}_{2}$ partial pressure. Figure 8 shows the good agreement between Eq. (14) 
and the experimental values for temperatures in the range $450-650^{\circ} \mathrm{C}$ and for $\mathrm{CO}_{2}$ partial pressure in the range $2-30 \mathrm{kPa}$.

$\tau(T, P)=\tau_{T}(T)+\left(\tau_{P}(P)-\tau_{P}\left(P_{0}\right)\right)$

where $P$ is the $\mathrm{CO}_{2}$ partial pressure (in $\mathrm{Pa}$ ), $T$ the temperature (in $\mathrm{K}$ ), $\tau_{\mathrm{T}}(\mathrm{T})$ et $\tau_{\mathrm{P}}(\mathrm{P})$ are given by Eqs. (12) and (13) respectively, and $\tau_{\mathrm{P}}\left(\mathrm{P}_{0}\right)=\tau_{\mathrm{P}}(5 \mathrm{kPa})=852 \mathrm{~s}$.

Table 1 lists the values of the areic reactivity of growth for each experimental condition. One can note that the areic reactivity of growth does not follow the classical Arrhenius law since the values decreased when the temperature increases (for $P\left(\mathrm{CO}_{2}\right)=5 \mathrm{kPa}$ ). Such a nonArrhenius behavior has already been seen in the case of decomposition reaction, as for example during the dehydration of trehalose dihydrate [18] and has been discussed elsewhere $[19,20]$.

To determine a theoretical law giving the variations of the areic reactivity of growth with both the temperature and the $\mathrm{CO}_{2}$ partial pressure, a mechanism of growth is proposed. Using the Kröger's notation [21], the following elementary steps are proposed to describe the mechanism of growth:

I) $\quad \mathrm{CO}_{2}$ adsorption at the $\mathrm{CaCO}_{3}$ surface

$\mathrm{CO}_{2}(g)+s \Leftrightarrow \mathrm{CO}_{2}-s$

II) External interface reaction with creation of an interstitial $\mathrm{CO}_{2}$ group in the $\mathrm{CaCO}_{3}$ phase

$\mathrm{CO}_{2}-s \Leftrightarrow \mathrm{CO}_{2 i, e x t}+s$ 
III) Diffusion of the interstitial $\mathrm{CO}_{2}$ group from the external interface to the internal one

$C O_{2 i, e x t} \Leftrightarrow C O_{2 i, \text { int }}$

IV) Internal interface reaction with creation of a building unit of $\mathrm{CaCO}_{3}$

$\mathrm{CO}_{2 i, \text { int }}+\mathrm{O}_{\mathrm{O}} \Leftrightarrow \mathrm{CO}_{3}$

In agreement with the kinetic model, the rate-determining step is assumed to be located at the internal interface, i.e. step (IV) is considered as the rate-determining step. By considering the steps (I), (II) and (III) at equilibrium, it is possible to calculate the expression of the areic reactivity of growth from Eq. (15).

$$
\phi_{I V}=k_{I V}\left[C O_{2 i, \text { int }}\right]-k_{I V}^{\prime}
$$

which leads finally to:

$$
\phi_{I V}=k_{I V} K_{I} K_{I I} P_{C O_{2}}\left(1-\frac{P_{e q}}{P_{\mathrm{CO}_{2}}}\right)
$$

with $k_{\mathrm{IV}}$ the rate coefficient of step IV, $k_{\mathrm{IV}}^{\prime}$ the rate coefficient of the inverse step, $K_{\mathrm{I}}$ and $K_{\mathrm{II}}$ the equilibrium constants of steps I and II respectively, $P_{\text {eq }}$ the equilibrium $\mathrm{CO}_{2}$ pressure (in $\mathrm{Pa}$ ) and $P_{\mathrm{CO} 2}$ the experimental $\mathrm{CO}_{2}$ partial pressure (in $\mathrm{Pa}$ ).

Since the rate coefficient $k_{\mathrm{IV}}$ and the equilibrium constants $K_{\mathrm{I}}$ and $K_{\mathrm{II}}$ obey Arrhenius' law, the expression of the areic reactivity of growth $\phi_{\mathrm{IV}}$ can be written:

$$
\phi_{I V}=A e^{-\frac{\Theta}{R T}} P_{C_{2}}\left(1-\frac{P_{e q}}{P_{\mathrm{CO}_{2}}}\right)
$$


where $A$ is a pre-exponential factor and $\Theta$ is a temperature coefficient equal to $E_{\mathrm{a}, \mathrm{IV}}+\Delta H_{\mathrm{I}}+$ $\Delta H_{\mathrm{II}} . E_{\mathrm{a}, \mathrm{IV}}$ is the real activation energy of step IV, $\Delta H_{\mathrm{I}}$ and $\Delta H_{\mathrm{II}}$ are the enthalpy variation of steps I and II respectively.

Eq. (17) has been matched to the values of $\phi$ deduced from the kinetic modeling (cf. Table 1) by adjusting the values of the parameters $A$ and $\Theta$. Fitting procedure was done by the least square method by considering each triplet $\left(\mathrm{T}, \mathrm{P}\left(\mathrm{CO}_{2}\right), \phi\right)$ of Table 1 and the value $\phi=0$ at $T=923 \mathrm{~K}$ and $P\left(\mathrm{CO}_{2}\right)=P_{\text {eq }}=993 \mathrm{~Pa}$. The best fit was obtained with $A$ equal to $6.3210^{-10} \mathrm{~mol} \mathrm{~m}^{-}$ ${ }^{2} \mathrm{~s}^{-1} \mathrm{~Pa}^{-1}$ and $\Theta$ equal to $-23147 \mathrm{~J} \mathrm{~mol}^{-1}$ and is represented by the continuous lines on Figure 9 and 10 which reports $\phi$ versus temperature and $\mathrm{CO}_{2}$ partial pressure respectively.

Eq. (17) allows to successfully represent $\phi$ values obtained from the kinetic modeling for different $\mathrm{CO}_{2}$ partial pressures at $923 \mathrm{~K}$ (Figure 10) and for different temperatures at $5 \mathrm{kPa}$ (Figure 9). Indeed differences between $\phi$ values obtained from the kinetic modeling and $\phi$ values calculated from Eq. (17) are in the range of $2-12 \%$ for each condition of temperature and $\mathrm{CO}_{2}$ partial pressure, except for the value obtained at $873 \mathrm{~K}$ and $5 \mathrm{kPa}$ for which the difference is about $25 \%$. So there is a good agreement between results obtained by fitting the kinetic rate equation to the experimental results, and the theoretical law $\phi\left(T, P\left(\mathrm{CO}_{2}\right)\right)$ determined from a mechanism of growth.

\section{Conclusion}

In a previous work [10], we highlighted that during $\mathrm{CaO}$ carbonation, there exists three distinct kinetic regimes. It had been noticed in particular that the first one corresponds to a 
chemical step control which simplifies the kinetic modeling since it is not necessary to take into account the gaseous transfers inside the porous aggregates.

In this first domain, the presence of an induction period as well as the shape of the kinetic curves were in favor of a kinetic model of transformation based on surface nucleation and growth processes involving a single nucleus per grain and inward isotropic growth. The rate determining step of $\mathrm{CaCO}_{3}$ growth was assumed to be located at the interface between $\mathrm{CaO}$ and $\mathrm{CaCO}_{3}$.

For each settled temperature or $\mathrm{CO}_{2}$ partial pressure, the experimental data were correctly described by the isotropic growth model with one nucleus per grain in the first domain and fitted values of the induction period and of the areic reactivity of growth could be obtained. Finally the dependence of the induction period and of the areic reactivity of growth on carbonation temperature and $\mathrm{CO}_{2}$ partial pressure could be determined. Using such dependence and the expression of the kinetic rate, it is possible to predict the kinetic behavior of $\mathrm{CaO}$ carbonation as far as the $\mathrm{CO}_{2}$ transport through the aggregates porosity remains fast relative to the chemical reaction rate.

\section{Acknowledgments}

The authors wish to thank Prof. Michel Soustelle for fruitful discussions

\section{References}

[1] Bhatia SK, Perlmutter DD. Unified treatment of structural effects in fluid-solid reactions. AIChE Journal. 1983;29:281-8.

[2] Silaban A, Harrison DP. High temperature capture of carbon dioxide: characteristics of the reversible reaction between $\mathrm{CaO}(\mathrm{s})$ and $\mathrm{CO}_{2}(\mathrm{~g})$. Chemical Engineering Communications. 1995; 137:177-190. 
[3] Bouquet E, Leyssens G, Schönnenbeck C, Gilot P. The decrease of carbonation efficiency of $\mathrm{CaO}$ along calcination-carbonation cycles: Experiments and modeling. Chemical Engineering Science. 2009;64:2136-46.

[4] Abanades JC, Alvarez D. Conversion Limits in the Reaction of $\mathrm{CO}_{2}$ with Lime. Energy \& Fuels 2003;17:308-15.

[5] Nikulshina V, Gálvez ME, Steinfeld A. Kinetic analysis of the carbonation reactions for the capture of $\mathrm{CO}_{2}$ from air via the $\mathrm{Ca}(\mathrm{OH})_{2}-\mathrm{CaCO}_{3}-\mathrm{CaO}$ solar thermochemical cycle. Chemical Engineering Journal. 2007;129:75-83.

[6] Grasa GS, Abanades JC, Alonso M, González B. Reactivity of highly cycled particles of $\mathrm{CaO}$ in a carbonation/calcination loop. Chemical Engineering Journal 2008;137:561-7.

[7] Borgwardt RH, Bruce KR. Effect of specific surface area on the reactivity of $\mathrm{CaO}$ with $\mathrm{SO}_{2}$. AIChE Journal 1986;32:239-46.

[8] Sun P, Grace JR, Lim C J, Anthony EJ. Determination of intrinsic rate constants of the $\mathrm{CaO}-\mathrm{CO}_{2}$ reaction. Chemical Engineering Science. 2008;63:47-56.

[9] Sun P, Grace JR, Lim CJ, Anthony EJ. A discrete-pore-size-distribution-based gas-solid model and its application to the $\mathrm{CaO}+\mathrm{CO}_{2}$ reaction. Chemical Engineering Science 2008;63:57-70.

[10] Rouchon L, Favergeon L, Pijolat M. Analysis of the kinetic slowing down during carbonation of $\mathrm{CaO}$ by $\mathrm{CO}_{2}$. J. Therm. Anal. Calorim. 2013;113:1145-55.

[11] Mess D, Sarofim AF, Longwell JP. Product layer diffusion during the reaction of calcium oxide with carbon dioxide. Energy Fuels. 1999;13:999-1005.

[12] Pijolat M, Soustelle M. Experimental tests to validate the rate-limiting step assumption 
used in the kinetic analysis of solid-state reactions. Thermochim. Acta. 2008;478:34-40.

[13] Favergeon L, Morandini J, Pijolat M, Soustelle M. A general approach for kinetic modeling of solid-gas reactions at reactor scale: application to kaolinite dehydroxylation. Oil and Gas Science and Technology. 2012; DOI: 10.2516/ogst/2012018.

[14] Besson R, Favergeon L. Atomic-Scale Study of Calcite Nucleation in Calcium Oxide. J. Phys. Chem. C. 2013;117:8813-21.

[15] de Leeuw NH, Watson GW, Parker SC. Atomistic simulation of the effect od dissociative adsorption of water on the surface-structure and stability of calcium and magnesium-oxide. J. Phys. Chem. 1995;99:17219-25.

[16] Besson R, Rocha Vargas M, Favergeon L. $\mathrm{CO}_{2}$ adsorption on calcium oxide: an atomicscale simulation study. Surf. Sci. 2012;606:490-5.

[17] Soustelle M. Heterogenous kinetics handbook. London: Wiley-ISTE London; 2010.

[18] Taylor LS, York P. Effect of particle size and temperature on the dehydration kinetics of trehalose dehydrate. Int. J. Pharm. 1998;167:215-21.

[19] Flynn JH. The 'temperature integral' - its use and abuse. Thermochim. Acta. 1997;300:83-92.

[20] Pijolat M, Favergeon L, Soustelle M. From the drawbacks of the Arrhenius-f( $\alpha)$ rate equation towards a more general formalism and new models for the kinetic analysis of solidgas reactions. Thermochim. Acta. 2011;525:93-102.

[21] Kröger FA, The Chemistry of Imperfect Crystals, North Holland, Amsterdam, 1964, p. 796.

\section{Figures}




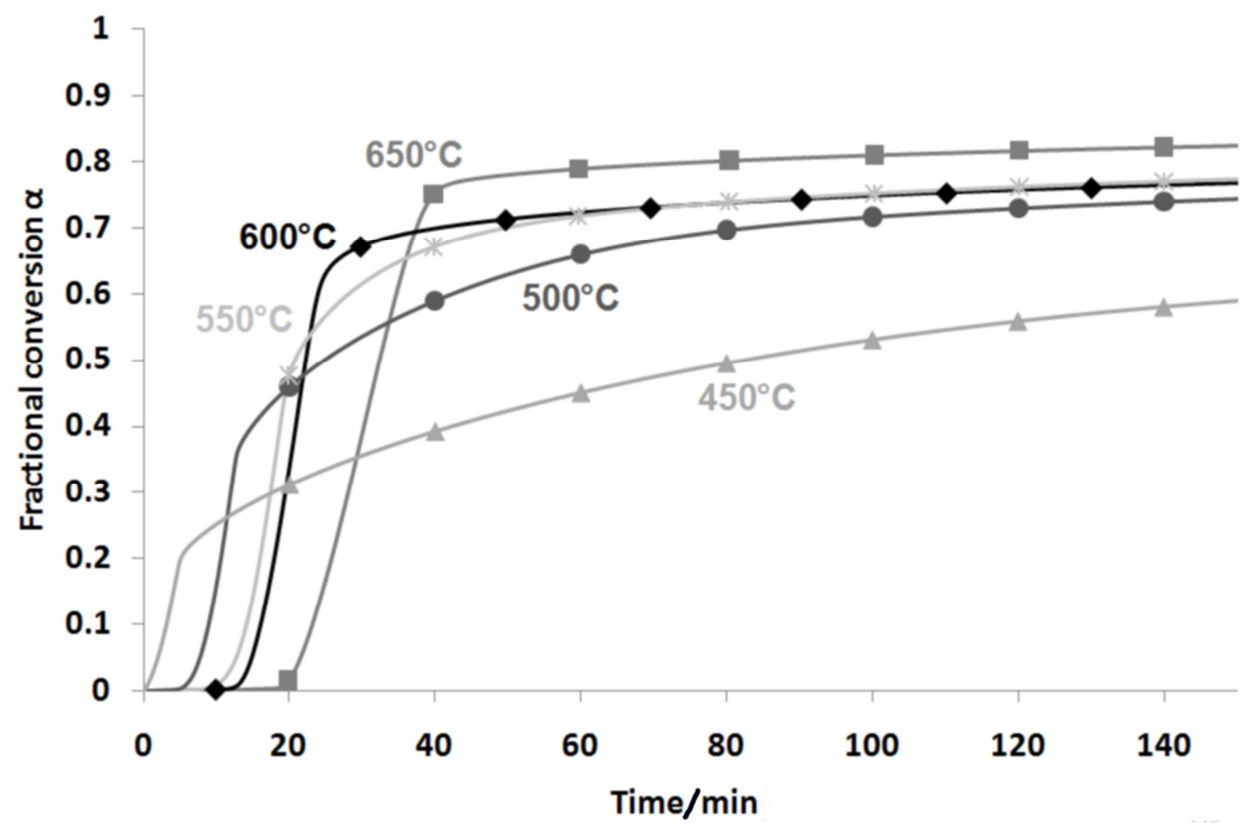

Figure 1: Isothermal and isobaric kinetic curves of $\mathrm{CaO}$ carbonation under a $\mathrm{CO}_{2}$ partial pressure of $5 \mathrm{kPa}$.
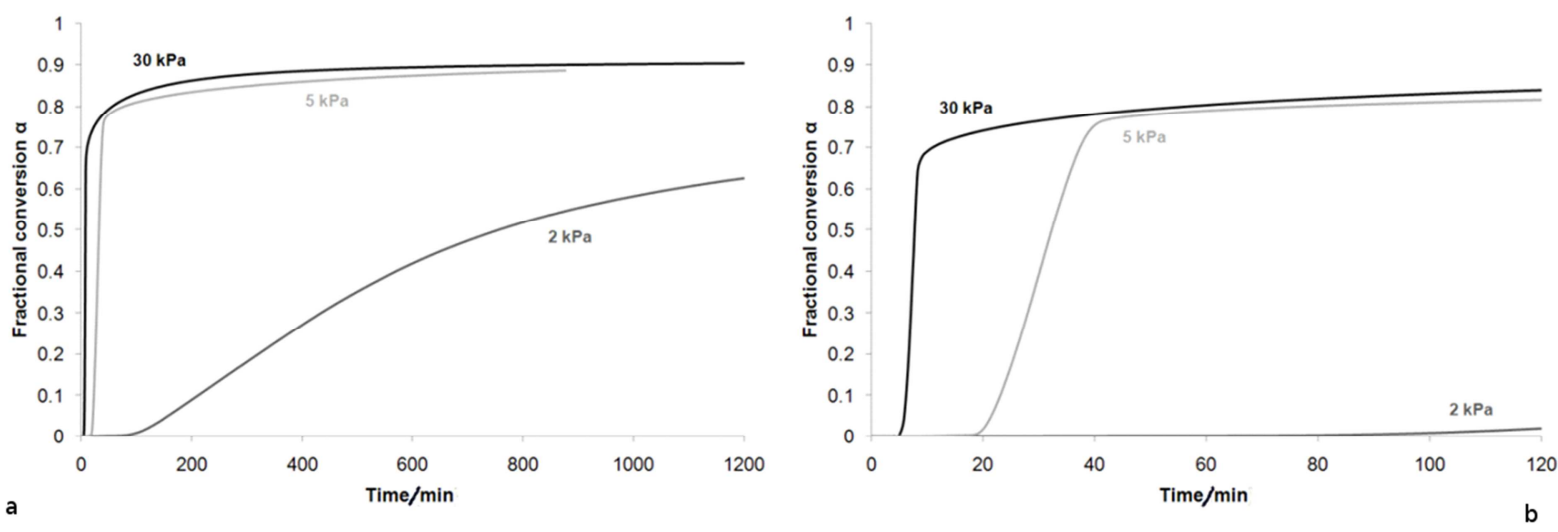

Figure 2: Isothermal and isobaric kinetic curves of $\mathrm{CaO}$ carbonation at $650^{\circ} \mathrm{C}$ : a between 0 and $1200 \mathrm{~min}$; b between 0 and $120 \mathrm{~min}$

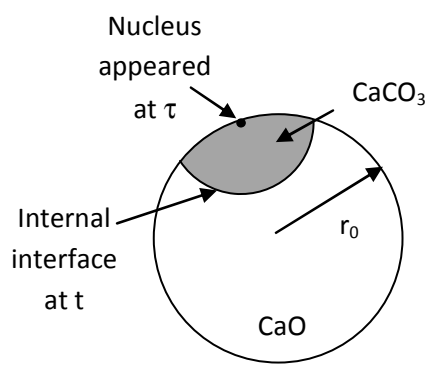


Figure 3: Scheme of the isotropic growth model with 1 nucleus per grain.

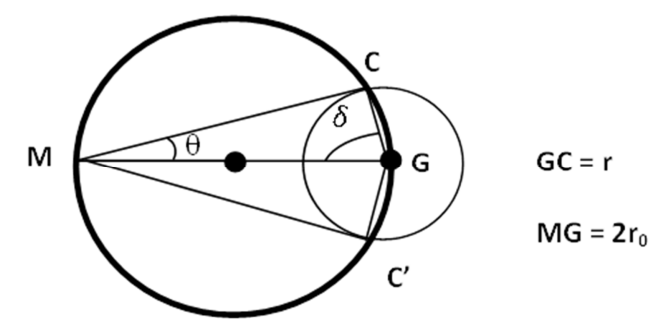

Figure 4: Evaluation of the area of $\mathrm{CaO} / \mathrm{CaCO}_{3}$ interface.
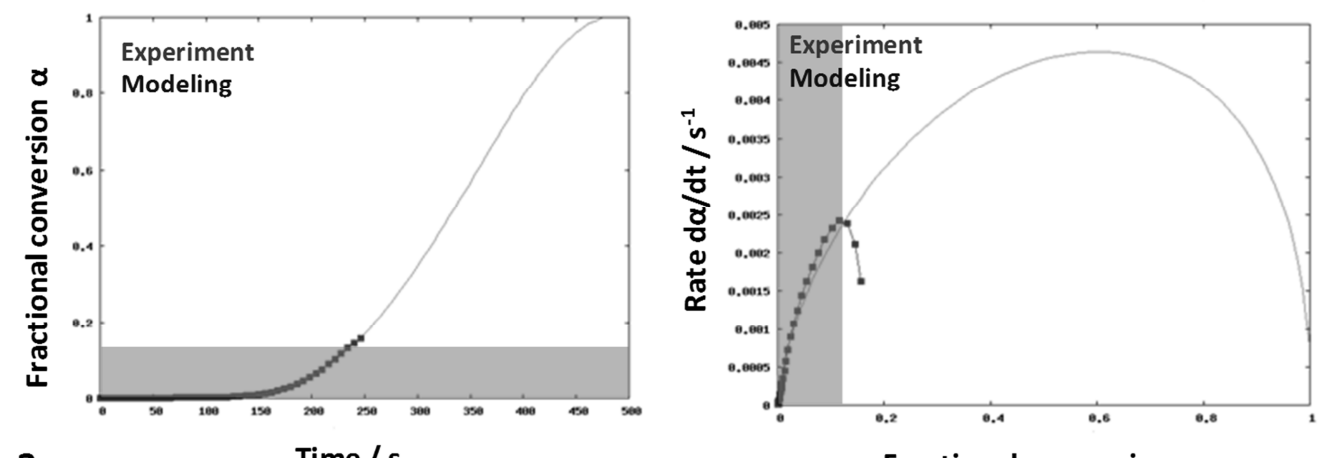

a

Time / s

Fractional conversion $\alpha$
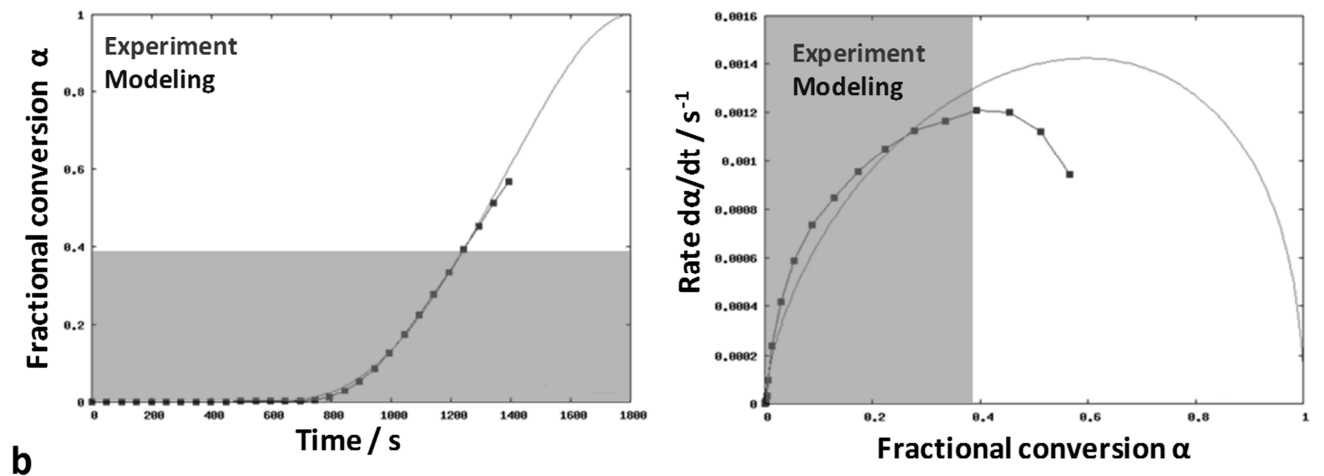

Figure 5: Curves $\alpha(t)$ and $\mathrm{d} \alpha / \mathrm{d} t(\alpha)$ for experiment at : a $723 \mathrm{~K}, 30 \mathrm{kPa}$ of $\mathrm{CO}_{2} ; \mathbf{b} 873 \mathrm{~K}, 5 \mathrm{kPa}$.

Experimental and calculated curves are represented by black curves with squares and by grey curves respectively. 


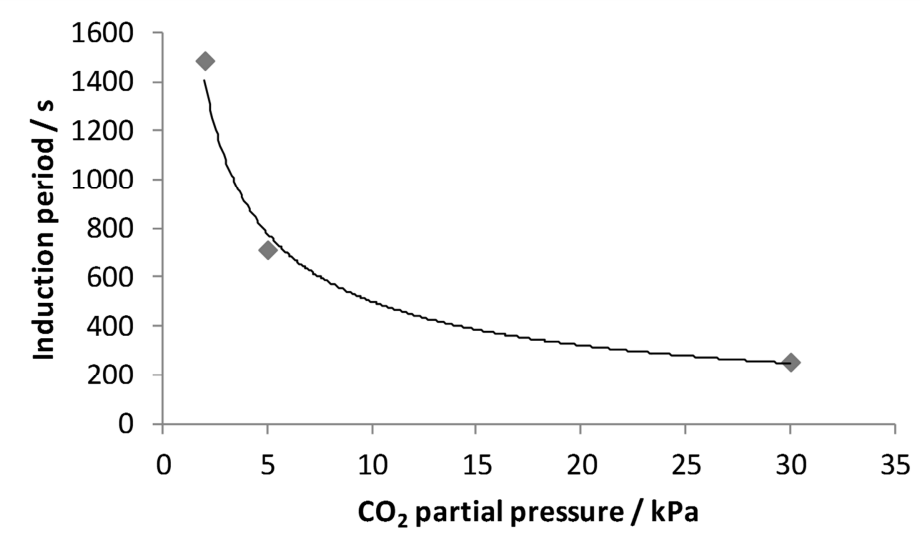

Figure 6: Variation of the induction period versus $\mathrm{CO}_{2}$ partial pressure for $\mathrm{T}=923 \mathrm{~K}$.

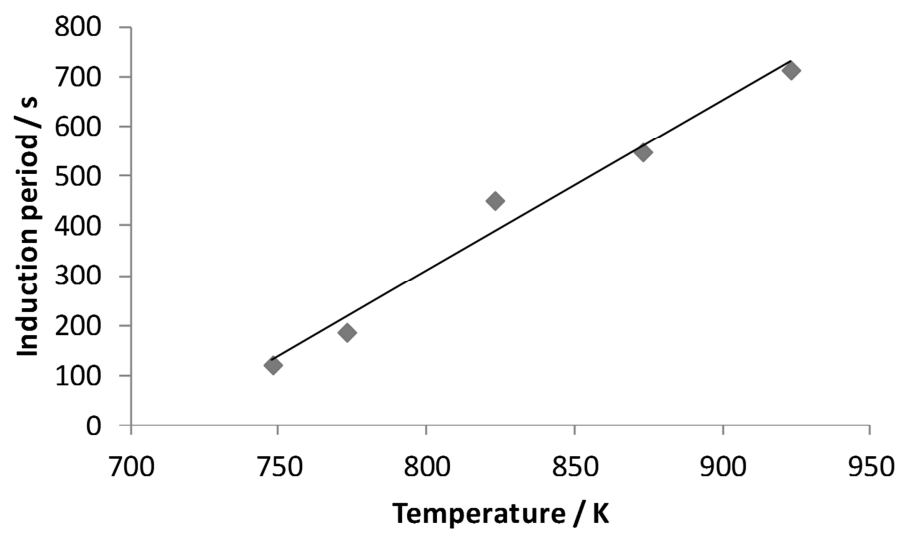

Figure 7: Variation of the induction period versus temperature for $\mathrm{P}\left(\mathrm{CO}_{2}\right)=5 \mathrm{kPa}$.

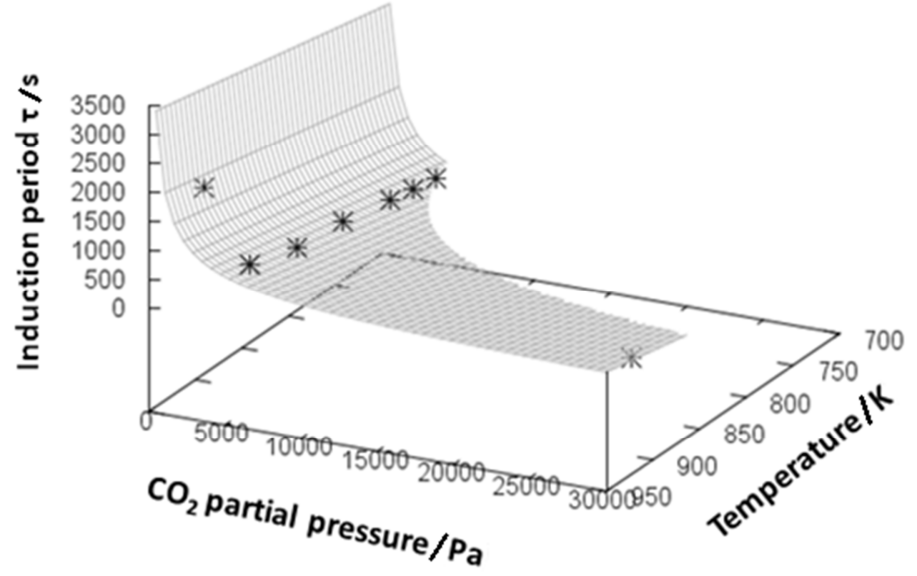

Figure 8: Comparison between experimental values of $\tau$ (crosses) and Eq. (16) (grey surface plot). 


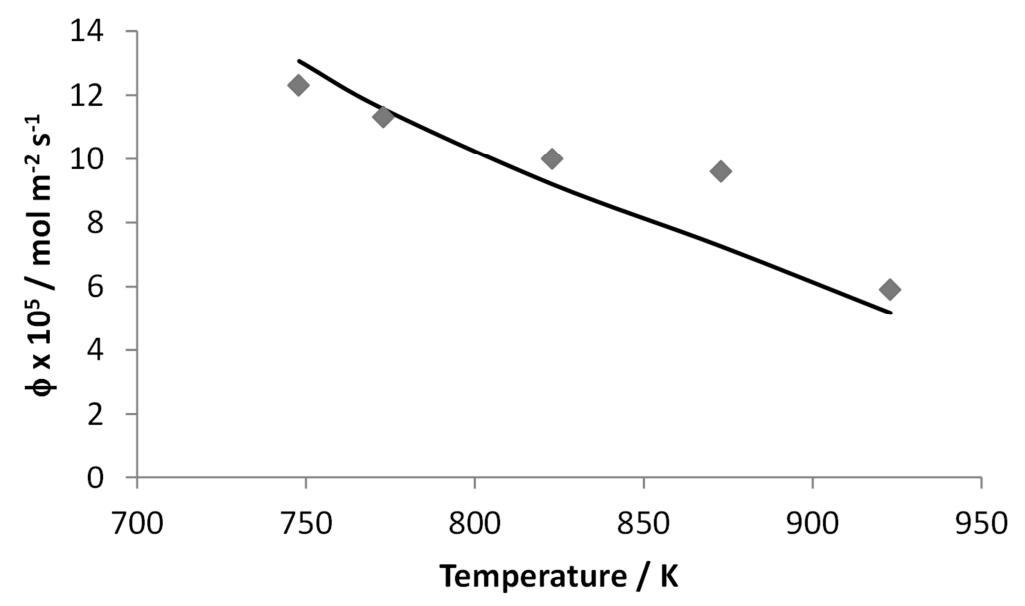

Figure 9: Variation of the areic reactivity of growth versus temperature for $\mathrm{P}\left(\mathrm{CO}_{2}\right)=5 \mathrm{kPa}$.

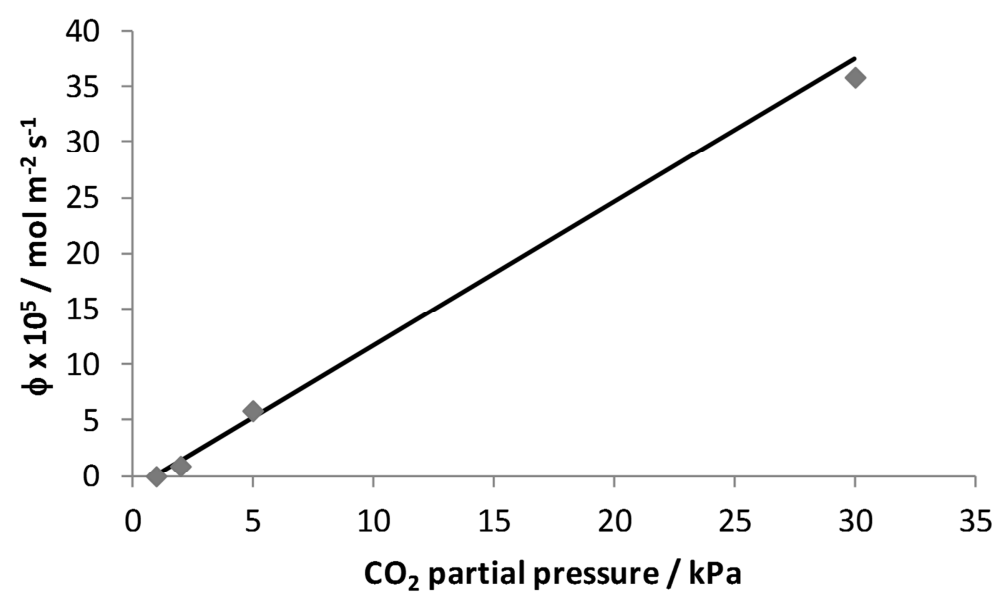

Figure 10: Variation of the areic reactivity of growth versus $\mathrm{CO}_{2}$ partial pressure for $\mathrm{T}=923 \mathrm{~K}$.

\section{Tables}

\begin{tabular}{|c|c|c|c|c|}
\hline $\mathrm{T} / \mathrm{K}$ & $\mathrm{P}\left(\mathrm{CO}_{2}\right) / \mathrm{kPa}$ & $\phi / \mathrm{mol} \mathrm{m}^{-2} \mathrm{~s}^{-1}$ & $\tau_{\text {simulation }} / \mathrm{s}$ & $\tau_{\exp } / \mathrm{s}$ \\
\hline 723 & 30 & $3.124010^{-4}$ & 95 & 93 \\
\hline 748 & 5 & $1.230410^{-4}$ & 123 & 87 \\
\hline 773 & 5 & $1.131010^{-4}$ & 187 & 172 \\
\hline 823 & 5 & $9.996110^{-5}$ & 452 & 348 \\
\hline 873 & 5 & $9.587410^{-5}$ & 549 & 447 \\
\hline 923 & 5 & $5.908110^{-5}$ & 714 & 696 \\
\hline 923 & 2 & $2.345710^{-6}$ & 1487 & 1889 \\
\hline 923 & 30 & $3.589110^{-4}$ & 256 & 249 \\
\hline
\end{tabular}

Table 1: Kinetic constants determined by adjustment $\left(\phi\right.$ and $\left.\tau_{\text {simulation }}\right)$ and directly from the experimental data $\left(\tau_{\exp }\right)$ for each experimental condition. 